\title{
O ESCANDÂLO CAMBRIDGE ANALYTICA: A MANIPULAÇÃO DE DADOS NA ERA DIGITAL
}

\section{CAMBRIDGE ANALYTICS SCANDAL: DATA HANDLING IN THE DIGITAL AGE}

VITTORIA ALVARES ANASTASIA

Graduanda em Direito, modalidade integral, pela Escola Superior Dom Helder Câmara. Belo Horizonte - MG. E-mail: vivianastasia@gmail.com

CAIO AUGUSTO SOUZA LARA Mestre e Doutor em Direito pela Faculdade de Direito da Universidade Federal de Minas Gerais - UFMG. Professor da Escola Superior Dom Helder Câmara. Pesquisador Associado ao Programa RECAJ-UFMG - Acesso à Justiça e Solução de Conflitos. Secretário de Comunicação do Conselho Nacional de Pesquisa e Pósgraduação em Direito - CONPEDI. Belo Horizonte-MG. E-mail: caiolarabh@yahoo.com.br.

\section{RESUMO}

O tema-problema da pesquisa que se pretende desenvolver é como o escândalo Cambridge Analytica trouxe a preocupação com a manipulação de dados de usuários na internet e até qual ponto empresas privadas podem invadir a privacidade individual e violar direitos fundamentais. A empresa Cambridge Analytica, através da coleta de dados individuais do Facebook, "transformou cliques em votos" (LAPOWSKY, 2018). Assim, algumas questões foram levantadas após o advento da associação do Facebook e da Cambridge Analytica, questionamentos esses 


\section{Personalidade Acadêmica Homenageada:}

Raymundo Juliano Feitosa (Universidade Federal do Rio Grande do Norte - UFRN)

principalmente sobre a legalidade das ações de ambas as corporações. Durante muitos anos, o acesso de dados dos amigos de um usuário era permitido pelos termos de uso do Facebook. Esta foi uma brecha explorada pela Cambridge Analytica no contexto do Brexit, por exemplo. Ademais, para Debord, (1968), o indivíduo moderno é um espectador e um consumista dos produtos e notícias, vivendo em uma submissão alienante ao império da mídia. Ao longo do século XX e princípio do século XXI, a mídia migrou do impresso para o digital, mas o homem ainda é bombardeado com publicidade e propaganda - ainda mais na era digital do que em qualquer outra, com empresas como Cambridge Analytica usando dos artifícios das redes sociais para atingir uma massa de indivíduos com publicidade especialmente direcionada a eles. Logo, em uma sociedade em que a maioria dos indivíduos é usuário constante de redes sociais, publicando informações pessoais e privadas na web, a temática da manipulação de dados torna-se de enorme importância, principalmente quando influencia na esfera política. Por isso, o escândalo se torna um dos alicerces para o despertar sobre indagações sobre a privacidade nas redes sociais, e, também, sobre seus impactos socioeconômicos. O problema objeto da investigação científica proposta é: quais as consequências do uso dos dados individuais e invasão da privacidade no escândalo Cambridge Analytica? A partir das reflexões preliminares sobre o tema, é possível afirmar inicialmente que, sob a luz dos eventos relacionados à empresa Cambridge Analytica e sua participação na campanha presidencial de Donald Trump em 2016, os usuários do Facebook foram manipulados através de publicidade na rede para, de tal forma, beneficiar determinado candidato. Consequentemente, supõe-se que esse escândalo foi o despertar de uma discussão sobre segurança digital e manipulação de dados durante eleições com intuito de favorecer determinadas figuras políticas. O objetivo geral do trabalho é analisar como a empresa Cambridge Analytica utilizou dados de uma pequena parcela de indivíduos para atingir milhões de usuários da rede social, bem como investigar a forma de manipulação das discussões em rede. A pesquisa que se propõe pertence à vertente metodológica jurídico-sociológica. No tocante ao tipo de investigação, foi escolhido, na classificação de Witker (1985) e Gustin (2010), o tipo jurídico-interpretativo. O raciocínio desenvolvido na pesquisa será predominantemente dedutivo. De acordo 
Personalidade Acadêmica Homenageada:

Raymundo Juliano Feitosa (Universidade Federal do Rio Grande do Norte - UFRN)

com a técnica de análise de conteúdo, afirma-se que se trata de uma pesquisa teórica, o que será possível a partir da análise de conteúdo dos textos doutrinários, normas e demais dados colhidos na pesquisa. A partir do exposto, conclui-se preliminarmente que o escândalo Cambridge Analytica agravou as discussões sobre a manipulação de dados, uma vez que a empresa foi uma das responsáveis pela publicidade nas redes sociais que contribuiu para grandes decisões políticas e sociais ao longo dos últimos anos. Além disso, na esteira dos acontecimentos supracitados, normas de proteção aos dados dos usuários como a Cloud Act (EUA) e a Lei Geral de Proteção de Dados (Brasil), foram criadas e no momento passam pelo teste de eficácia jurídica e social.

PALAVRAS CHAVE: direito à tecnologia; manipulação de dados; escândalo Cambridge Analytica; redes sociais; internet.

\section{REFERÊNCIAS}

DEBORD, Guy. Sociedade do espetáculo. Rio de Janeiro: Contraponto, 2000.

FARRANHA, Ana Cláudia et al. Democracia, participação e redes sociais digitais: desafios contemporâneos da política e do direito, Revista Jurídica - UNICURITIBA, Curitiba, v. 3, n. 44, pp. 117-140, 2016. Disponível em: http://revista.unicuritiba.edu.br/index.php/RevJur/article/view/1740/1134. Acesso em 20 maio 2019.

GUSTIN, Miracy Barbosa de Sousa; DIAS, Maria Tereza Fonseca. (Re)pensando a pesquisa jurídica: teoria e prática. 3ª . ed. Belo Horizonte: Del Rey, 2010.

HAN, Byung-Chul. No Enxame: perspectivas do digital. Tradução do original Agonie des Eros por Enio Paulo Giachini. Petrópolis: Vozes, 2018.

HERN, Alex. Cambridge Analytica: how did it turn clicks into votes?. The Guardian. Londres: 62 maio 2018.2 Disponível em: https://www.theguardian.com/news/2018/may/06/cambridge-analytica-how-turnclicks-into-votes-christopher-wylie. Acesso em: 1 maio 2019.

LAPOWSKY, Isse. How Cambridge Analytica sparked the great privacy awakening. Wired. São Francisco: 17 mar 2018. Disponível em: https://www. wired.com/story/cambridge-analytica-facebook-privacy-awakening/. Acesso em: 20 abr. 2019. 
Personalidade Acadêmica Homenageada:

Raymundo Juliano Feitosa (Universidade Federal do Rio Grande do Norte - UFRN)

STROUD, Court. Cambridge Analytica: The Turning Point In The Crisis About Big Data. Forbes. Nova lorque: 30 abr 2018. Disponível em: https://www.forbes.com/sites/courtstroud/2018/04/30/cambridge-analytica-theturning-point-in-the-crisis-about-big-data/\#b4fa41b48ecc. Acesso em: 5 maio 2019.

WITKER, Jorge. Como elaborar uma tesis en derecho: pautas metodológicas y técnicas para el estudiante o investigador del derecho. Madrid: Civitas, 1985.

WOLF, Mauro. Teorias da Comunicação de Massa. $8^{\text {a }}$ ed. São Paulo: Presença, 2003. 